\title{
Diminutivos em -j nas línguas Jê Setentrionais
}

\author{
Andrey Nikulin \\ Pesquisador colaborador, Universidade de Brasília, Brasil / \\ Pós-doutorando, Université d'Ottawa, Canadá \\ https://orcid.org/0000-0003-2237-564X
}

\begin{abstract}
The goal of this article is to identify the previously undescribed derivational affix $-j$, which occurs in some lexemes in the Northern Jê languages. I examine 17 cognate sets instantiating a mismatch between the presence of a stem-final $-j$ in some languages and its absence in other languages. It is shown that the occurrence of the "non-etymological" instances of the element $-j$ is more frequent in diminutives, suggesting that $-j$ could be a low-productivity affix. Therefore, the hypothesis is that the original function of Proto-Northern Jê $*_{-} j$ was that of deriving diminutives, even though in some cases its morphological status may have turned opaque. I also propose that the Proto-Northern Jê morpheme in question was borrowed from Tupi-Guarani languages.
\end{abstract}

KEYWORDS: Northern Jê languages; Unproductive morphology; Historical linguistics; Language contact

RESUMO: Este artigo objetiva analisar o afixo derivacional $-j$, ainda não descrito na literatura, que está presente na construção morfológica de alguns lexemas das línguas Jê Setentrionais. São examinados 17 conjuntos de cognatos em que algumas línguas apresentam $-j$ no final da raiz, ao passo que outras línguas carecem de qualquer contraparte desse segmento. Constata-se que as ocorrências do elemento -j "não etimológico" são mais frequentes em derivações diminutivas, sendo provável que se trate de um afixo de baixa produtividade. Assim, apresento a hipótese de que o elemento $*_{-j}$ do Proto-Jê Setentrional tenha tido originalmente a função de um sufixo diminutivo, embora em alguns casos seu status morfológico possa ter se tornado opaco. É proposto, ainda, que o morfema em questão tenha entrado na protolíngua via empréstimo das línguas Tupi-Guarani.

PALAVRAS-CHAVE: Línguas Jê Setentrionais; Morfologia não-produtiva; Linguística histórica, Contato de línguas

\section{Introdução}

O ramo Jê Setentrional (família Jê, tronco Macro-Jê) é um conjunto de línguas indígenas estreitamente relacionadas entre si, faladas nos estados do Pará, Mato Grosso, Tocantins e Maranhão. Todas as línguas Jê Setentrionais possuem um par de sufixos derivacionais altamente produtivos cuja função se assemelha à dos afixos de grau diminutivo e aumentativo na língua portuguesa. Por exemplo, na língua dos Gavião-Pykobjê são documentadas formas como caxiire 'estrela', caapucre 'oiti-da-chapada', em oposição a caxiiteh 'estrela grande', caapucteh 'oiti-da-mata' (Sá Amado 2004: 134), em que se identificam os sufixos diminutivo/atenuativo - re e aumentativo/intensificador -teh (alomorfe de - 'teh que ocorre após sílabas pesadas). Morfemas cognatos existem nas demais línguas Jê Setentrionais, permitindo a reconstrução de $*_{-} r e$ e $*_{-}{ }^{2} t i$ para a língua ancestral desse agrupamento (doravante PJS $=$ Proto-Jê Setentrional).

Neste trabalho, empreende-se uma tentativa de demonstrar que as línguas Jê Setentrionais apresentam resquícios de um terceiro sufixo de grau, não identificado nos trabalhos existentes, que possui a forma -j (grafado como - $i$ em Parkatêjê; Araújo 1993: 266). Esse sufixo, que não é necessariamente segmentável em todas as línguas contemporâneas, 
aparenta possuir ou ter possuído uma carga semântica próxima ou idêntica à do diminutivo/atenuativo -re, diferenciando-se deste por não ser produtivo.

A metodologia deste estudo consiste na análise de discrepâncias formais observadas em uma série de conjuntos de cognatos. Por exemplo, os termos para 'minhoca' nas línguas Apinajé e Krahô são, respectivamente, kutõj e cutõ. Esses itens são apenas parcialmente cognatos, pois a consoante $j$ do Apinajé carece de qualquer contraparte em Krahô (normalmente Apinajé $j$ corresponde regularmente a Krahô $j$ em todas as posições, cf. Nikulin \& Salanova 2019). Discrepâncias semelhantes foram identificadas em 17 conjuntos de cognatos, situação essa que necessita de uma explicação. A solução que proponho a seguir é morfológica: postulo que o elemento -j pode ser, talvez ainda sincronicamente, analisado como um sufixo de grau diminutivo.

$\mathrm{O}$ artigo é estruturado da seguinte maneira. Na seção $\mathbf{1}$ explicito as convenções de representação dos dados neste trabalho. A seção $\mathbf{2}$ apresenta as línguas Jê Setentrionais e os sufixos de grau nelas encontrados. Em seguida, na seção 3, são reproduzidos os dados em que se baseia o estudo. Por fim, o status morfológico do elemento -j é discutido na seção 4, e as considerações finais complementam o artigo.

\section{Representação dos dados}

Todos os dados linguísticos das línguas contemporâneas são reproduzidos neste artigo em sua representação ortográfica, em conformidade com as grafias atualmente em uso nas respectivas comunidades de fala e divergindo, em alguns casos, das convenções usadas nas fontes consultadas. As raízes das palavras analisadas estão destacadas em negrito. Os temas relacionais (isto é, aqueles que exigem a expressão de seu argumento interno em sua margem esquerda) são indicados com hífen à esquerda (por exemplo, Kajkwakhrattxi -khra 'filho'). A fim de tornar o texto mais legível, não indico a segmentação morfológica das palavras por meio de hifens, a menos que seja indispensável para a discussão.

As formas reconstruídas seguem a proposta de Nikulin e Salanova (2019), com duas importantes modificações sugeridas pelo estudo comparativo de Ribeiro Silva (2020) no que diz respeito à reconstrução de vogais longas e da oclusiva glotal em coda silábica. A duração vocálica é reconstruída com base nos reflexos em Gavião-Pykobjê e Krĩkatí (cf. Ribeiro Silva 2020: 178-90). A oclusiva glotal em coda silábica, representada neste artigo como a preglotalização da consoante subsequente, é preservada em Apinajé, Gavião-Pykobjê, Krĩkatí, Canela-Apànjêkra e Canela-Memõrtũmre (cf. Ribeiro Silva 2020: 151). Nikulin e Salanova (2019) não reconhecem essas características como contrastivas na protolíngua e reconstroem alguns pares de raízes homônimas, tais como *kucê 'espinha' e *kucê 'ficar de pé.PL', embora as línguas contemporâneas apresentem reflexos contrastivos, a exemplo de Gavião-Pykobjê cohhii 'espinha', - 'coh'hi 'ficar de pé.PL' (Pries 2008: 19, 30). Na reconstrução atualizada, tanto a duração vocálica como a oclusiva glotal encontradas em Gavião-Pykobjê são reconhecidas como retenções: Proto-Jê Setentrional *kucê: 'espinha', *_'ku'cê 'ficar em pé'.

\section{Línguas Jê Setentrionais}

O ramo Jê Setentrional integra a família Jê, do tronco linguístico Macro-Jê. As línguas dos seguintes povos são classificadas como Jê Setentrionais:

1. Kajkwakhrattxi (= Tapayuna, Beiços-de-Pau), originários da região entre os rios Arinos e Sangue (bacia do Tapajós, noroeste de Mato Grosso) e residentes hoje na T.I. CapotoJarina (rio Xingu, nordeste de Mato Grosso), tendo passado pelo Parque Indígena do 
Xingu, aonde foram transferidos em 1971 em decorrência do etnocídio que haviam sofrido em seu território original;

2. Kĩsêdjê (= Suyá), do rio Suiá-Miçu (bacia do Xingu, nordeste de Mato Grosso), onde se instalaram na segunda metade do século XIX, vindo da bacia do Tapajós;

3. Mẽbêngôkre (com pequenas diferenças dialetais entre as variedades faladas pelos Kayapó e Xikrin; um terceiro dialeto, não mais utilizado, era falado pelos Irã'ãmrãnhre), do sul e sudeste do Pará e do nordeste de Mato Grosso;

4. Apinajé, da região do Bico do Papagaio (Tocantins);

5. os povos Timbira, que de acordo com critérios linguísticos podem ser classificados em quatro conjuntos claramente definidos: ${ }^{1}$

a. Gavião do Pará, incluindo os grupos Parkatêjê, Kỳikatêjê e Akrãtikatêjê (embora não haja estudos linguísticos acerca da língua deste último grupo), hoje reunidos na T.I. Mãe Maria, localizada entre as cidades de Marabá/PA e Bom Jesus do Tocantins/PA, onde os Parkatêjê residem tradicionalmente; os demais grupos foram transferidos para lá vindos de regiões localizadas águas acima pelo rio Tocantins, no estado do Maranhão (Kỳikatêjê), e nas cabeceiras dos rios Capim e Moju, próximo a Jacundá/PA (Akrãtikatêjê);

b. o conjunto "Central", incluindo os Gavião-Pykobjê e os Krĩkatí, das cabeceiras do Grajaú e do Pindaré (Maranhão); também pertenciam a esse grupo os Cree pym cati ji, do médio Grajaú, bem como os Krẽjê do Cajuapara, das proximidades de Imperatriz/MA (ver Nimuendajú 1946);

c. o conjunto "Meridional", incluindo os povos Canela-Apànjêkra (da T.I. Porquinhos/MA), Canela-Memõrtũmre (= Ràmkôkamekra, da T.I. Kanela/MA), Krahô (da T.I. Kraolândia/TO) e possivelmente ainda alguns povos que não vivem mais de forma autônoma, como os Xokamekra, os Põrekamekra e os Kẽncatêjê;

d. o conjunto "Setentrional", integrado por alguns povos que não vivem mais de maneira autônoma, tais como os Timbira do Araparitíua, do médio Gurupi (provavelmente originários da região do Pindaré), bem como os Krẽjê do Bacabal e os Cukôjkamekra, da região entre o baixo Grajaú e o médio Mearim (ver Nimuendajú 1946); os dialetos que pertencem ao conjunto Setentrional provavelmente não são mais falados e não serão considerados no restante deste artigo.

\footnotetext{
${ }^{1}$ No que diz respeito à posição das variedades Parkatêjê, Kỳikatêjê, Gavião-Pykobjê, Krĩkatí, Canela-Apànjêkra, Canela-Memõrtũmre e Krahô, adoto a classificação de Nikulin (2020: 7), aceita também por Ribeiro Silva (2020: 78), exceto pelos rótulos "Timbira Central" e "Timbira Meridional", que são propostos aqui pela primeira vez. Para as variedades Cree pym cati ji, Krẽjê do Cajuapara, Xokamekra, Põrekamekra, Kẽncatêjê, Timbira do Araparitíua, Krẽjê do Bacabal e Cukôjkamekra, baseio-me nas informações fornecidas por Nimuendajú (1946). As isoglossas que sustentam a divisão do complexo dialetal Timbira em quatro conjuntos incluem:

- a fusão de $* k^{h} \mathrm{e} * k$ em um fonema e a perda da oclusiva glotal em coda silábica em Gavião do Pará;

- o uso de reflexos de *co: 'cachorro' e * $k^{h} \hat{o} p$ 'vento' em Timbira "Central" (em vez de *rop 'cachorro' e * $k^{h} \hat{o k}$ 'vento', como nos demais dialetos Timbira);

- o uso de reflexos de $*_{-}$' $k^{h} a t$ 'base, tronco, coxa' e *ampo 'coisa, algo' em Timbira "Meridional" (em vez de *-' $k^{h}$ rat 'base, tronco, coxa' e *mpo 'coisa, algo', como nos demais dialetos Timbira);

- a fricativização da oclusiva aspirada $* k^{h}>[\mathrm{x}]$ (ou até mesmo [J]) em Timbira "Setentrional".
} 
De acordo com as classificações mais antigas, o ramo Jê Setentrional inclui ainda a língua Panará, falada hoje no rio Iriri, na divisa dos estados do Pará e Mato Grosso. Neste estudo, seguindo Castro Alves (2010: 454) e Nikulin e Salanova (2019: 535), consideramos que o Panará não faz parte desse agrupamento.

Em todas essas línguas, os sufixos $*_{-}$re (diminutivo ou atenuativo) e $*_{-}^{2} t i$ (aumentativo ou intensificador) do Proto-Jê Setentrional foram preservados. Esses morfemas podem ser afixados a nomes e verbos descritivos, mas normalmente são incompatíveis com verbos de outras classes; sua ocorrência, muitas vezes lexicalizada, é extremamente comum em nomes de plantas e animais. Apresento a seguir os reflexos de $*_{-}$re e $*_{-}^{2} t i$ nas línguas contemporâneas (1). ${ }^{2}$

(1) a. Kajkwakhrattxi -re, -txi (Camargo 2010: 99; 2015: 79-80, 84)

b. $\quad$ Kĩsêdjê -re, -txi (Nonato et al. 2012)

c. Mẽbêngôkre -re/-te/-ne/-e, -ti (Reis Silva 2001: 24)

d. Apinajé -re, -hti/-ti (Oliveira 2003: 257-9; Albuquerque 2011: 79-80)

e. Parkatêjê/Kỳikatêjê -re, -ti (Ferreira 2003: 57, 126; Ferreira Silva 2014)

f. Gavião-Pykobjê/Krĩkatí -re, - 'teh/-teh (Sá Amado 2004: 36-7, 40, 135-6; Pries 2008: 95, 98)

g. Canela/Krahô -re, -hti/-ti (Castro Alves 2004: 48, 52; Albuquerque e Krahô 2016: 53-4, 136-7)

Um afixo diminutivo não cognato foi descrito em Kajkwakhrattxi (-tĩ, ou inclusive -tĩ-re; Camargo 2015: 79-80) e Kĩsêdjê (-sĩ-re; Guedes 1993: 107). Essas duas línguas são estreitamente relacionadas uma à outra, constituindo o sub-ramo Tapajoara do ramo Jê Setentrional. A correspondência entre Kajkwakhrattxi $t$ e Kĩsêdjê $s$ é regular, pois ambas consoantes continuam a oclusiva aspirada $* t^{h}$ do Proto-Tapajoara (Nikulin 2020: 85), e o sufixo diminutivo $*_{-} t^{h}(-r e)$ pode ser reconstruído para o Proto-Tapajoara. A ausência de cognatos conhecidos desse afixo em outras línguas Jê Setentrionais sugere que se trata de uma inovação restrita ao ramo Tapajoara.

\section{Dados}

Nesta seção, apresento uma lista de itens lexicais das línguas Jê Setentrionais contemporâneas que apresentam uma aproximante palatal a mais (grafada como $-j$ ou $-i$ ), que não faz parte dos respectivos étimos na protolíngua. As raízes morfológicas de cada cognato estão destacadas em negrito.

\footnotetext{
${ }^{2}$ Os alomorfos separados por barra são condicionados fonologicamente. Em Mẽbêngôkre, o rótico do sufixo

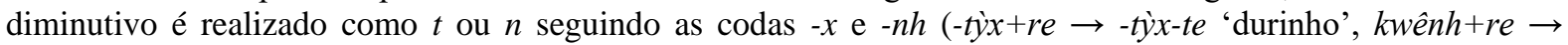
$k w e ̂ n h-n e$ 'passarinho') e cai após as codas -t e -n (kêt +re $\rightarrow$ kêt-e 'periquito', prĩn $+r e \rightarrow$ prĩn-e 'pequi miúdo'). Em Apinajé, Gavião-Pykobjê, Krĩkatí, Canela e Krahô, a oclusiva glotal do sufixo aumentativo (grafada como $h$ ou ') desaparece seguindo consoantes ou vogais longas (compare Canela-Apànjêkra rohti 'sucuri' vs. cuxujti 'pato'; Castro Alves 2004: 27-8).
} 
(2) PJS *ku:tõ: 'animal vermiforme (minhoca, minhocuçu, cobra-de-duas-cabeças)'

a. Kajkwakhrattxi kuthõj 'minhoca' (Camargo 2010: 66)

b. Mẽbêngôkre kutõj 'minhocuçu; cobra-cega' (Passos 2018: 57; Salanova, comunicação pessoal)

c. Apinajé kutõj 'minhoca, lombriga', kutõj akutã krã(ti) 'cobra-de-duas-cabeças, cobra-cega' (Oliveira 2005: 397; Albuquerque 2012: 43)

comparem-se as formas sem $-j$ :

d. Parkatêjê $\boldsymbol{k u t o ̃ r e ~ ' v e r m e , ~ m i n h o c a ' , ~} \boldsymbol{k u t o ̃ t i ~ ' m i n h o c a ~ g r a n d e ’ ~ ( A r a u ́ j o ~ 2 0 1 6 : ~ 1 5 3 ) ~}$

e. Gavião-Pykobjê/Krîkatí coohtõo 'vermes, minhoca, lombriga' (Pries 2008: 21)

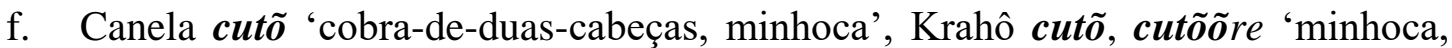
verme, lombriga', cutõ japjêa 'solitária', cutõ pihho 'verminoses' (Castro Alves 2004: 51; Grupp 2015: 54; Albuquerque 2016: 20, 73, 161-3)

(3) PJS *-rz̃ 'filhote de peixe'

a. Parkatêjê -rãire 'filhote de peixe' (Araújo 2016: 211)

b. Canela-Memõrtũmre tep rãjre 'piabinha' (Grupp 2015: 186)

comparem-se as formas sem $-j$ :

c. Mẽbêngôkre teprãre 'peixe pequeno, filhote de peixe' (Salanova, comunicação pessoal)

d. Apinajé tep rãre 'piaba, pirosca, piabinha, peixinho', tep rã ry 'piaba-comprida' (Oliveira 2005: 410; Albuquerque 2012: 71)

e. Canela-Memõrtũmre tep rãre, tep rãhti 'piabinha', Krahô teppe rãre (sem glosa, termo usado em um canto no ritual do Peixe e Lontra) (Grupp 2015: 186; Krahô 2020: 45, 47)

(4) PJS *- $p o$ 'ser achatado, largo'

a. Mẽbêngôkre -poj, -pojre, -pojti 'ser chato, achatado; curvar-se' (Passos 2018: 50, 60, 171; Salanova, comunicação pessoal)

b. Gavião-Pykobjê/Krĩkatí - 'pojre 'ser um pouco chato' (Pries 2008: 39) 
comparem-se as formas sem $-j$ :

c. Kajkwakhrattxi -ho em kõwnuhotxi 'arraia', thêhotxi 'carrapato médio', wàtho 'arara', ntwâjhotxi 'urubu' (Camargo 2010: 59, 61, 80; Kajkwakhrattxi et al. 2018, item 2018-35.002)

d. Kĩsêdjê -ho 'ser achatado’ (Nonato et al. 2012: 7)

e. Mẽbêngôkre -po, -pore, -poti 'ser achatado' (em compostos; Passos 2018: 60, 74; Salanova, comunicação pessoal)

f. Apinajé -hpo 'ser achatado, largo', pĩhpo 'cadeira, banco' (Oliveira 2005: 401; Albuquerque 2012: 63, 65)

g. Parkatêjê -po 'achatado, largo' (Araújo 2016: 197)

h. Gavião-Pykobjê/Krĩkatí -'po 'ser reto (por ex. uma tábua)', -’po'teh 'ser chato, largo’ (Pries 2008: 39)

i. Canela -hpo 'largo'; Krahô pîhpo ‘banco' (Grupp 2015: 125; Albuquerque e Krahô 2016: 100)

(5) PJS *kakrã 'xixá, axixá'

a. Apinajé $\boldsymbol{k a}(\boldsymbol{h}) \boldsymbol{k r a \tilde { j } t i}$ (Albuquerque 2012: 33)

comparem-se as formas sem -j:

b. Gavião-Pykobjê/Krĩkatí cacrỹ'teh (Pries 2008: 13)

c. Krahô cakrãa(a) re (Albuquerque 2016: 53, 95, 129)

(6) PJS *ku’krz̃ 'tipo de abelha (xupé ou arapuá)'

a. Mẽbêngôkre kukrãjti 'xupé', kukrãjre 'bora-brava' (Kayapó et al. 2007: 171; Passos 2018: 74)

comparem-se as formas sem -j:

b. Kajkwakhrattxi kukhrãtxi 'tipo de abelha' (Kayapó et al. 2007: 56)

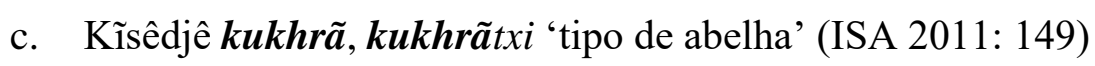

d. Apinajé $\boldsymbol{k u k r \tilde { a } ( h ) t i}$ 'arapuá, xupé', kukrã nhy kamrêk 'arapuá vermelha' (Albuquerque 2012: 42)

e. Parkatêjê $\boldsymbol{k} \boldsymbol{u} \boldsymbol{k} \boldsymbol{r a \tilde { r } e}$ 'jupé', $\boldsymbol{k} \boldsymbol{u k r a \tilde { t } t}$ 'abelha que fica grudada (faz caixa) no meio do pau' (Araújo 2016: 146)

f. Gavião-Pykobjê/Krĩkatí coh'crỹ 'tipo de abelha' (Pries 2008: 19) 
g. Canela-Memõrtũmre cuhkrãhti 'tipo de térmita (como abelha de mel)'; Krahô cukrãhti 'xupé', cuhkrãre 'arapuá' (Grupp 2015: 43; Andrade et al. 2002: 20)

(7) PJS *(a) ygrê 'esp. de tatu'

a. Parkatêjê krêire 'tatu-rabo-de-couro' (Araújo 2016: 137)

comparem-se as formas sem $-j$ :

b. Kajkwakhrattxi angrêtxi 'tatu-bola' (Camargo 2010: 66)

c. Kĩsêdjê angrê hotxi 'tatu-peba', angrêtxi 'tatu-de-rabo-pelado' (Nonato et al. 2012: 3)

d. Apinajé hagrêre 'tatu-rabo-de-couro', hagrêhti 'tatu-zumbi' (Oliveira 2005: 102, 363, 411; Albuquerque 2012: 23)

e. Gavião-Pykobjê criire 'tatu-china' (Sá Amado 2004: 134)

(8) PJS *- $*_{-} t \tilde{o}, * a:-t \tilde{o}$ 'irmão'

a. Mẽbêngôkre -tõjre 'irmão (para os kutapure, ou caçulas)' (Lea 2012: 175)

comparem-se as formas sem $-j$ :

b. Kĩsêdjê -tho 'irmão’ (Nonato et al. 2012: 26)

c. Mẽbêngôkre -tõ 'irmão' (Lea 2012: 175)

d. Apinajé -htõ , atõ 'irmão’ (Oliveira 2005: 179, 411; Albuquerque 2012: 18, 49, 71)

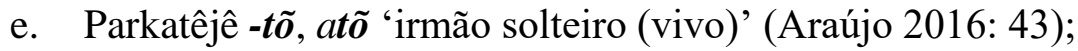

f. Gavião-Pykobjê/Krĩkatí - 'tõ 'irmão’ (Sá Amado 2004: 78; Pries 2008: 42)

g. Canela -htõ , Krahô at̃̃ 'irmão' (Castro Alves 2004: 47, 65, 123, 124, 176; Grupp 2015: 128; Albuquerque e Krahô 2016: 43)

(9) PJS *karə 'veado-catingueiro'

a. Parkatêjê karàire 'veado-fuboca' (Araújo 2016: 119)

comparem-se as formas sem -j:

b. Mẽbêngôkre karà(re) 'veado', karàre krajkunõ 'Mazama rufina' (Kayapó et al. 2007: 186; Salanova, comunicação pessoal)

c. Apinajé karà 'veado' (Oliveira 2005: 388; Albuquerque 2012: 36)

d. Parkatêjê karàjaxy 'catingueira', literalmente 'rabo de veado' (Araújo 2016: 119)

e. Gavião-Pykobjê/Krĩkatí carỳ (Sá Amado 2004: 163; Pries 2008: 17) 
f. Canela carà ‘tipo de veado pequeno', Krahô carà(re) 'veado-catingueiro' (Castro Alves 2004: 42, 169; Grupp 2015: 34; Albuquerque 2016: 22, 38, 139, 142; Albuquerque e Krahô 2016: 40, 109)

(10) PJS *-'tu 'capim; raiz medicinal ou comestível'

a. Apinajé htuj 'mato, moita' (Oliveira 2005: 316, 411)

comparem-se as formas sem $-j$ :

b. Kĩsêdjê hwĩthu 'remédio' (Suyá et al. 1999: 93; Suyá et al. 2012: 62, 66)

c. Mẽbêngôkre pitu 'remédio, raiz' (Kayapó et al., 2007: 76, 178)

d. Apinajé htu 'mato, moita', pĩhtu pihtu 'raiz útil (por ex., cenoura, gengibre, açafrão)' (Oliveira 2005: 315, 411; Albuquerque 2012: 63)

e. Parkatêjê atuti 'capim para gado comer' (Araújo 2016: 45)

f. Gavião-Pykobjê/Krĩkatí - 'toh 'raiz de mandioca', a'tooh 'capim; raízes e plantas medicinais', pẽh’ toh 'raiz de árvore' (Sá Amado 2004: 141; Pries 2008: 2, 42, 90)

g. Canela/Krahô - htu 'tubérculo, raiz comestível', ahtu 'erva, grama, capim' (Castro Alves 2004: 38, 78; Grupp 2015: 8, 129; Albuquerque 2014: 55, 59)

(11) PJS *-'kra 'filho, filha'

a. Krĩkatí a'crajre 'crianças' (Pries 2008: 1)

b. Canela-Apànjêkra/Krahô ahkrajre 'criança' (Castro Alves 2004: 42, 58, 59, 63, 86, 130; Albuquerque 2014: 20, 57; Albuquerque e Krahô 2016: 47, 48, 101; Krahô 2020: $48,53,57)$

comparem-se as formas sem $-j$ :

c. Kajkwakhrattxi -khra 'filho' (Camargo 2015: 134, 156, 174, 213)

d. Kĩsêdjê -khra 'filho; filho da irmã do pai (ego feminino)' (Nonato et al. 2012: 13)

e. Mẽbêngôkre -kra 'filho/a; BC, WZC, FBSC... (ego masculino), ZC, HBC, FZC, FBDC... (ego feminino); filhote' (Lea 2012: 175)

f. Apinajé -hkra(re) 'filho/a, filhote' (Oliveira 2005: 393; Albuquerque 2012: 38, 48)

g. Parkatêjê -kra 'filho/a, filhote' (Araújo 2016: 133)

h. Gavião-Pykobjê - 'cra 'filho/a, filhote'; a'craare 'crianças'; Krîkatí -'cra 'filho, filha, filhote' (Sá Amado 2004: 141; Pries 2008: 1, 32) 
i. Canela (ambos dialetos)/Krahô -hkra(re) 'filho/a; criança', Canela-Memõrtũmre ahkra(re) 'criança' (Castro Alves 2004: 176; Grupp 2015: 2, 118-9; Albuquerque 2016: 47; Albuquerque e Krahô 2016: 47, 48)

(12) PJS *kôkñõ: *kõkñõ: 'ingá'

a. Parkatêjê kukjãire 'ingá', kukjãitikatutututi 'um tipo de ingá' (Araújo 2016: 145)

b. Krahô $\boldsymbol{k} \tilde{\boldsymbol{o}} \boldsymbol{k} \boldsymbol{j} \tilde{\boldsymbol{o} j} \boldsymbol{j}$ 'ingá' (Albuquerque 2016: 95, 129)

comparem-se as formas sem $-j$ :

c. Kĩsêdjê kõngnhõtôtxi 'ingá' (Suyá et al. 1999: 19; Suyá et al. 2012: 18)

d. Mẽbêngôkre kôknhõ kôti 'ingá' (Kayapó 2007: 218)

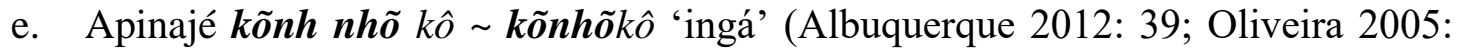
391)

f. Gavião-Pykobjê/Krĩkatí cõc jõ̃̃̃xuи pỳr 'pé de ingá' (Pries 2008: 1, 32)

(13) PJS *-_krã 'montanha, morro' (extensão semântica de *-'krã 'cabeça')

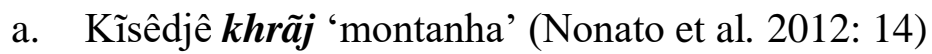

b. Mẽbêngôkre krãj akrãj ‘elevação, montículo, morro’ (Passos 2018: 161, 164, 169; Salanova, comunicação pessoal)

comparem-se as formas sem $-j$ :

c. Kajkwakhrattxi $\boldsymbol{k h r \tilde { a } t x i}$ 'montanha, morro, serra' (Kajkwakhrattxi et al. 2018, item 2018-35.002)

d. Apinajé kẽn krã (hprêk) 'morro, serra', akrãjarô 'morro, serra' (Oliveira 2005: 181, 391; Albuquerque 2012: 14)

d. Parkatêjê akrãre 'ladeira', akrãtikatiti 'serra' (Araújo 2016: 29)

e. (?) Gavião-Pykobjê/Krĩkatí $a$ 'crỹy' cỳ 'crosta da terra, casca' (Pries 2008: 1)

f. Canela-Memõrtũmre ahkrã jacot crà 'ilha' (Grupp 2015: 2)

Em Canela-Memõrtũmre kẽn càre kẽn càjre 'colina pequena, morrinho' (Grupp 2015: 153), formas com e sem -j foram atestadas como variantes, apesar de não haver cognatos conhecidos em outras línguas.

Nos exemplos apresentados na lista acima, na hipótese de coocorrência do elemento $-j$ e do sufixo diminutivo produtivo - $r e$, este último é sempre precedido de $-j$, o que resulta na sequência -j-re (cf. 3a-b, 4a-b, 6a, 7a, 8a, 9a, 11a-b, 12a). Somente na língua Kajkwakhrattxi, foram encontrados dois lexemas em que a ordem é inversa: o sufixo -re é seguido (e não precedido) do elemento - $j$ (14-15). Poderia tratar-se de um elemento idêntico àquele discutido 
acima; alternativamente, $-j$ na sequência - $r e-j$ poderia ser uma contração lexicalizada do sufixo de plural coletivo $-j \hat{e}$.

(14) PJS *by 'moças'

a. Kajkwakhrattxi wyre-j 'mulher' (Camargo 2015: 87)

comparem-se as formas sem $-j$ :

b. Kĩsêdjê pyre-jêe 'meninas' (com sufixos fossilizados de diminutivo e plural; Nonato et al. 2012: 22; Suyá et al. 1999: 11, 61; Suyá et al. 2012: 28)

c. Gavião-Pykobjê/Krĩkatí pyh ji 'moças, mulheres' (Pries 2008: 94)

d. Canela/Krahô pyjêe 'mulheres' (Castro Alves 2004: 141; Grupp 2015: 178; Albuquerque 2014: 54)

(15) PJS *ygə:jy:(-re) 'rapazes'

a. Kajkwakhrattxi ngàtyrej 'criança' (Camargo 2010: 52; 2015: 87)

comparem-se as formas sem $-j$ :

b. Kajkwakhrattxi ngàtyjêe 'meninos' (Camargo 2015: 167)

c. Kĩsêdjê ngáty 'menino', ngátyrejê (com sufixos fossilizados de diminutivo e plural; Nonato et al. 2012: 19; Suyá et al. 1999: 61; Suyá et al. 2012: 15, 70)

c. Mẽbêngôkre ngàdjyre 'meninos' (Passos 2018: 15, 34, 107)

d. Gavião-Pykobjê/Krĩkatí cỳy xyyh ji, cỳy xyyhre 'rapazes não casados' (Pries 2008: 25)

Finalmente, apenas em Canela e Krahô, foram encontrados pares de formas que se diferenciam, além da presença ou ausência de $-j$, pela altura da vogal final do tema (16-18).

(16) PJS *bor 'pau' e *_'ka 'casca'

a. Canela-Memõrtũmre pàrkàre pàrkỳjre 'peixe pequeno' (Grupp 2015: 172) compare um composto semelhante sem -j em outras línguas:

b. Mẽbêngôkre bàjkàti(re) 'acari' (Salanova, comunicação pessoal)

c. Apinajé pàr kàhti 'acari (cascudo)' (Albuquerque 2012: 60)

d. Parkatêjê pàrkàti 'acari' (Araújo 2016: 190) 
PJS *-gaygro 'estar quente'

a. Canela-Memõrtũmre -cacro 'estar quente' -cacrujre 'estar morno' (Grupp 2015: 30)

comparem-se as formas sem $-j$ nas demais línguas:

b. Kajkwakhrattxi -kanghro 'estar quente, calor' (Camargo 2010: 46; 2015: 119, 159)

c. Kĩsêdjê -kangro 'estar quente, arder' (Nonato et al. 2012: 10)

d. Mẽbêngôkre -kangro 'estar quente' (Reis Silva 2001: 23)

c. Apinajé -kangro 'quente, morno, febril; esquentar' (Oliveira 2005: 387; Albuquerque 2012: 32)

d. Parkatêjê -kakro 'quentura, esquentar', -kakroti 'quente, com febre' (Araújo 2016: 112)

e. Gavião-Pykobjê/Krĩkatí -cacro ‘ser/estar quente, ter febre’ (Sá Amado 2004: 115; Pries 2008: 13)

f. Krahô -cacro(hti) (Albuquerque e Krahô 2016: 59, 71)

PJS *-'kra'filho/a, filhote'

a. Krahô -hkra(a)re -hkryjre 'criança, filhote' (Albuquerque 2016: 63, 75, 127; Albuquerque e Krahô 2016: 47, 52, 100, 103, 152; Krahô 2020: 32, 47, 53, 57, 59).

(ver 11 para os cognatos em outras línguas)

Nesta seção, argumentou-se que as línguas Jê Setentrionais possuem resquícios de um terceiro afixo, não mais produtivo, cuja forma pode ser reconstruída como PJS *-j. Na próxima seção, é discutida a possibilidade de que o elemento - $j$ tenha tido originalmente a função de um sufixo diminutivo, embora em alguns casos seu status morfológico possa ter se tornado opaco.

\section{Discussão}

$\mathrm{Na}$ seção anterior, vimos que o elemento "não etimológico" -j foi encontrado em algumas palavras de cada uma das línguas Jê Setentrionais: Kajkwakhrattxi (2a, 14a, 15a), Kĩsêdjê (13a), Mẽbêngôkre (2b, 4a, 6a, 8a, 13b), Apinajé (2c, 5a, 10a), Parkatêjê (3a, 7a, 9a, 12a), Gavião-Pykobjê (4b), Krĩkatí (4b, 11a), Canela-Apànjêkra (11b), Canela-Memõrtũmre (3b, 16a, 17a) e Krahô (11b, 12b, 18a). Como há diferença em cada caso do conjunto de línguas que apresentam o -j "não etimológico", é descartada a hipótese de que se trata de uma inovação restrita a um agrupamento específico de línguas. À luz da existência de variantes com e sem o -j em um mesmo lexema, em uma mesma língua (cf. 3b/e, 10a/d, 16a, 18a), é plausível propor que o elemento - $j$ desempenha, ainda sincronicamente, uma função morfológica, pelo menos em algumas línguas.

A alta frequência do elemento - $j$ nas derivações diminutivas em - $r$ é um fato que chama a atenção, seja na ordem -j-re (3a, 3b, 4a, 4b, 6a, 7a, 8a, 9a, 11a, 11b, 12a e Canela kẽn càjre; com o alçamento da vogal também 16a, 17a, 18a) ou na ordem inversa, -re-j (apenas em 
Kajkwakhrattxi; 14a, 15a). Em contraste às derivações diminutivas, as ocorrências de $-j$ são consideravelmente mais raras nas derivações aumentativas (4a, 5a, 6a, 12b). Em alguns casos, as derivações diminutivas em -j-re parecem formar pares mínimos com os temas não derivados sem -j: Gavião-Pykobjê/Krĩkatí - 'po-j-re vs. - 'po ou -po-'teh (4b/h), Mẽbêngôkre -tõ-j-re /-tõ $(8 \mathrm{a} / \mathrm{c})$, Canela-Memõrtũmre -cacru-j-re vs. -cacro (17a). No caso do termo para 'criança', identifica-se a derivação lexicalizada, constituída do prefixo de possuidor genérico $a$-, do elemento -j e do diminutivo -re (Krîkatí $a$-' $c r a-j-r e$, Canela-Apànjêkra/Krahô $a$-hkra-j-re), contrastando com a raiz morfológica - 'cra / -hkra, sem o elemento -j (11a/h, 11b/i).

A evidente correlação entre a ocorrência de $-j$ e do sufixo diminutivo - $r$ e permite hipotetizar que a função original do elemento -j poderia ter envolvido a semântica de atenuação ou diminutivização. Com efeito, a semântica de quase todos os itens envolvidos é compatível com a hipótese de que sua consoante final seja analisável como (ou diacronicamente provenha de) um afixo diminutivo: muitos lexemas analisados denotam animais de pequeno porte ('minhoca', 'filhote de peixe', 'abelha-xupé ou bora-brava', 'peixe-pequeno') ou pelo menos menores que o protótipo ('tatu-rabo-de-couro', 'veado-fuboca'); outros se referem a pessoas relativamente mais novas ('irmão caçula', três termos para 'criança'); um termo diz respeito a um estado mais moderado ('estar morno') que aquele designado por sua contraparte não derivada ('estar quente').

Nos seis termos restantes ('mulher', 'ser achatado/largo', 'montanha/morro', 'xixá/axixá', 'mato/moita', 'ingá'), a contribuição semântica de -j é menos clara, mas não é impensável que em algumas línguas o sufixo -j (que possuía, outrora, uma função diminutiva) tenha sido reanalisado como parte de algumas raízes, perdendo o significado original, em um processo de opacização (fossilização) morfológica. Uma mudança semelhante ocorreu na história da língua portuguesa, em que as palavras joelho e orelha (<latim geniculum e auricula, diminutivos de genū 'joelho' e auris 'orelha', respectivamente) não são sincronicamente analisáveis como diminutivos.

Dessa forma, hipotetizo que em Proto-Jê Setentrional, além do sufixo diminutivo produtivo $*_{-}$re, existia ainda um sufixo $*_{-} j$ com uma função semelhante ou idêntica, que podia ocorrer apenas em temas que terminavam em vogal e era de baixa frequência lexical. Esses dois sufixos podiam ainda coocorrer, seguindo a ordem *-j-re (a ordem inversa é encontrada apenas na língua Kajkwakhrattxi e provavelmente é inovadora). No complexo dialetal CanelaKrahô, foram encontrados três lexemas em que o acréscimo de $-j$ faz com que a vogal precedente sofra alçamento: pàrkà $\rightarrow$ pàrkỳjre, -cacro $\rightarrow$-cacrujre, -hkra $\rightarrow$-hkryjre. Como não foram identificados fenômenos análogos em outras línguas, conclui-se que se trata de uma inovação exclusiva a esse complexo dialetal.

Quanto à possível origem desse afixo, destaco sua semelhança formal e semântica com o sufixo diminutivo das línguas Tupi-Guarani, que em várias línguas dessa família possui a forma - 'i, como em Suruí-Aikewara (Lopes 2014: 102), ou -i/-ĩ, como em Kamaiurá (Seki 2000: 372) ou Avá-Canoeiro (Borges 2006: 134-5). Como não foram encontrados cognatos de PJS *-j em outras línguas Jê, é concebível que se trata de um empréstimo das línguas TupiGuarani. $^{3}$

Futuras pesquisas em campo junto a falantes das línguas Jê Setentrionais poderão corroborar ou rejeitar a hipótese formulada neste artigo. Possíveis rumos de investigação incluem a documentação de outros lexemas com um -j "não etimológico", bem como a

\footnotetext{
${ }^{3} \mathrm{Um} /$ a parecerista anônimo/a indaga se foram identificados "argumentos não só linguísticos, mas socio-históricos que sustentem a hipótese de empréstimo para o elemento analisado". Até o presente, tais evidências não foram identificadas. Ressalta-se que a possibilidade de difusão via empréstimo diz respeito a um período em que o ProtoJê Setentrional ainda não havia se cindido em múltiplas línguas, evento que ocorreu entre os séculos II e VII (Salanova e Nikulin 2020: 54, nota 5). Por se tratar de uma época relativamente remota, as evidências referentes ao possível contato são necessariamente indiretas.
} 
descrição semântica das línguas Jê Setentrionais com vistas a verificar se há alguma diferença semântica entre os pares "mínimos" (tais como tep rãre vs. tep rãire 'piabinha' em CanelaMemõrtũmre).

\section{Considerações finais}

No exame de 17 conjuntos de cognatos das línguas Jê Setentrionais, foi identificada a discrepância entre a presença de $-j$ em algumas variedades e sua ausência em outras. Foi proposto que o elemento - $j$ na margem direita das raízes desempenhe, ou tenha desempenhado no passado, o papel de um sufixo diminutivo, que aparenta ter coexistido na protolíngua com sua contraparte mais produtiva, PJS *-re. Com isso, os resultados tendem a contribuir na ampliação do conhecimento da morfologia, tanto sincrônica como histórica, das línguas Jê Setentrionais.

\section{Agradecimentos}

Agradeço a Andrés Pablo Salanova por seus comentários acerca da forma e da semântica dos termos da língua Mẽbêngôkre citados neste artigo, a dois/duas pareceristas anônimos/as da LIAMES pelas sugestões que contribuíram para o aperfeiçoamento do manuscrito, bem como ao Conselho de Pesquisa em Ciências Humanas e Sociais do Canadá (SSHRC), que viabilizou esta pesquisa por meio de uma bolsa Insight (número 435-2018-1173, Pesquisador Principal: Andrés Pablo Salanova). Quaisquer erros ou equívocos são de minha exclusiva responsabilidade.

\section{Referências}

Albuquerque, Francisco Edviges (coord.) (2011). Gramática pedagógica da língua Apinajé. Goiânia: Editora da PUC-Goiás. http://uft.edu.br/lali/uploads/10_gramaticapedagogicaapinaye3.pdf

Albuquerque, Francisco Edviges (org.) (2012). Dicionário escolar Apinayé: Panhĩ kapẽr-kupẽ kapẽr, Apinayéportuguês. Belo Horizonte: Editora da Faculdade de Letras-UFMG. http://www.uft.edu.br/lali/uploads/11_dicinionariomec.pdf

Albuquerque, Francisco Edviges (org.) (2014). Geografia Krahô: pjê kãm ampo itajê nã carõ. Campinas: Pontes Editores. http://www.uft.edu.br/lali/uploads/geografia2014.pdf

Albuquerque, Francisco Edviges (org.) (2016). Ciências Krahô. Campinas: Pontes Editores. http://www.uft.edu.br/lali/uploads/cie\%CC\%82nciaskraho\%CC\%822016.pdf

Albuquerque, Francisco Edviges; Krahô, Renato Yahé (orgs.) (2016). Gramática pedagógica Krahô. Campinas: Pontes Editores. http://www.uft.edu.br/lali/uploads/grama\%CC\%81ticakraho\%CC\%822016.pdf

Andrade, Aldanei Menezes de; Carlos Antônio Bezerra Salgado; Jussiânia Borges Corrêa; Maria Eliza Requejo Ribeiro Leite; Nélson César Destro Jr.; Valéria Medeiros Andrade (2002). Abelhas nativas brasileiras: conservação ambiental. Brasília: FUNAI/DEDOC.

https://acervo.socioambiental.org/acervo/documentos/abelhas-nativas-brasileiras-conservacaoambiental

Araújo, Leopoldina (1993). Fonologia e grafia da língua da comunidade Parkatêjê (Timbira). In Lucy Seki (org.) (1993). Lingüística indígena e educação na América Latina, pp. 265-271. Campinas: Editora da UNICAMP. http://www.etnolinguistica.org/biblio:araujo-1993-fonologia

Araújo, Leopoldina (2016). Dicionário Parkatêjê-Português. Belém: edição da autora.

Borges, Mônica Veloso (2006). Aspectos fonológicos e morfossintáticos da língua Avá-Canoeiro (Tupi-Guarani) (Tese de doutorado em linguística). Campinas: Universidade Estadual de Campinas. http://repositorio.unicamp.br/jspui/handle/REPOSIP/270406 
Camargo, Nayara da Silva (2010). Língua Tapayúna: aspectos sociolingüísticos e uma análise fonológica preliminar (Dissertação de mestrado em linguística). Campinas: Universidade Estadual de Campinas. http://repositorio.unicamp.br/jspui/handle/REPOSIP/270867

Camargo, Nayara da Silva (2015). Tapayuna (Jê): aspectos morfossintáticos, históricos e sociolinguísticos (Tese de doutorado em linguística). Campinas: Universidade Estadual de Campinas. http://repositorio.unicamp.br/jspui/handle/REPOSIP/270864

Castro Alves, Flávia de (2004). O Timbira falado pelos Canela Apãniekrá: uma contribuição aos estudos da morfossintaxe de uma língua (Tese de doutorado em linguística). Campinas: Universidade Estadual de Campinas. http://repositorio.unicamp.br/jspui/handle/REPOSIP/270880

Castro Alves, Flávia de (2010). Evolution of alignment in Timbira. International Journal of American Linguistics 76(4): 439-75. https://doi.org/10.1086/658054

Ferreira, Marília de Nazaré de Oliveira (2003). Estudo morfossintático da língua Parkatêjê (Tese de doutorado em linguística). Campinas: Universidade Estadual de Campinas. http://repositorio.unicamp.br/jspui/handle/REPOSIP/270362

Ferreira Silva, Marília de Nazaré (2014). Descrição fonético-fonológica do Kyikatêjê. Letras de Hoje 49(1): 56-65. https://doi.org/10.15448/1984-7726.2014.1.14864

Grupp, Bernhard (2015). Dicionário Canela: Canela-Português-Inglês, Português-Canela, Inglês-Canela. $2^{\mathrm{a}}$ ed. Barra do Corda: Missão Cristã Evangélica do Brasil.

ISA-Instituto Socioambiental (2011). Almanaque Socioambiental. Parque Indígena do Xingu: 50 anos. São Paulo: Instituto Socioambiental.

https://www.socioambiental.org/pt-br/o-isa/publicacoes/almanaque-socioambiental-parque-indigenado-xingu-50-anos-0

Kajkwakhrattxi, Nokêrê; Kajkwakhrattxi, Orengô; Beauchamp, Jérémie; Lapierre, Myriam (2018). Kajkwakhrattxi field materials (Survey of California and Other Indian Languages, 2018-35). Berkeley: UC Berkeley. https://doi.org/10.7297/X2RF5SH0

Kayapó, Bepkũm Mẽkrãgnõtire; Metuktire, Patoit; Mẽtyktire, Ropni; Txucarramãe, Megaron; Mẽtyktire, Iobal; Mẽtyktire, Bepkrit; Mẽtyktire, Kômỳj; Mẽtyktire, Tàkàkkrã; Metuktire, Karopi; Mekragnotire, Pakyj-i; Kayapó, Doto Tàkàk-ire; Kayapó, Bekwỳjti; Mẽkrãgnõtire, Kute-ê; Mẽkrãgnõtire, Kôkômati; Suyá, Hwinkã Tapajúna; Tapajúna, Wentykarôrô; Tapajúna, Roptykti; Kayapó, Màntino; Kayapó, Xikatô; Kayapó, Brajre; Panará, Symakriti; Panará, Akâ; Panará, Tesêja; Kayapó, Banò; Kaiapó, Bebĩn; Txucarramãe, Beboiti Metuktire; Tapajúna, Bengrôj; Metuktire, Bepdjàti; Mekragnoti-re, Bepdjỳ-re; Kayapó, Bepkĩre; Mekragnoti-re, Bepkôre; Mekragnoti-re, Bepkyj; Mekragnoti, Bepnhi; Mekragnoti-re, Bep-oiô; Kaiapó, Bep-te; Kaiapó, Beptôti; Kaiapó, Betire; Mekragnoti-re, Bere; Metuktire, Êngri; Txucarramãe, Ikumã; Panará, Jotikiã; Kaiapó, Karanhĩn; Metuktire, Katàptire; Kayapó, Kôkôba; Kaiapó, Kôkôkumẽm; Txucarramãe, Kokopiêti Yurui Trumai; Kayapó, Kremajti; Metuktire, Kremôrô; Kayapó, Kukrytkra; Metuktire, Meningô; Tapajúna, Màntxi-i; Panará, Krekreansâ Mikre; Karopi, Mro-re; Mekragnoti-re, Nhàkpokti; Tapajúna, Orengô; Kaiapó, Pàtkà-re; Metuktire, Patkôre; Panará, Perankô Pokre; Panará, Ponto Tepikô; Metuktire, Prejkỳre; Metuktire, Pydjàkoro; Panará, Sâkiêrã; Kaiapó, Tàkàk-ê; Mekragnoti-re, Tàkàkkudjôti; Kayapó, Takakmy; Metuktire, Tàkàktũm; Metuktire, Tekreranti; Mekragnoti-re, Tõmêajkwa; Kaiapó, Tom-êre; Mekragnoti-re, Topti; Metuktire, Txuakre; Panará, Txokrãn Metuktire; Metuktire, Waiwai; Tapayuna, Weneti Suiá (2007). Mẽbêngôkre mẽ, Panãra mẽ, Tapajúna nhõ pyka karõ nẽjã. Panãra mẽ Mẽbêngôkre mẽ Tapajúna jõ kypa prẽpi hãkia. Tapajúna mẽ Mẽbêngôkre mẽ Panãra nhõ hwyka karõ rõ tujarẽ na itha. Atlas dos territórios Mẽbêngôkre, Panará e Tapajúna. Colíder: Programa de Formação de Professores Mẽbêngôkre, Panãra e Tapajúna. https://issuu.com/programampt/docs/atlas junho07

Krahô, Tais Põcuhto (2020). Tep mẽ Têêre. Rio de Janeiro: Pachamama. https://www.alfabecantar.com.br/tep-me-teere/

Lea, Vanessa (2012). Riquezas intangíveis de pessoas partíveis: os Mẽbêngôkre (Kayapó) do Brasil Central. São Paulo: EDUSP/FAPESP.

Lopes, Jorge Domingues (2014). Uma interface da documentação linguística e modelos lexicográficos para línguas indígenas brasileiras: uma proposta para o Suruí-Aikewára (Tese de doutorado em linguística). Brasília: Universidade de Brasília, Brasília. https://repositorio.unb.br/handle/10482/18271 
Nikulin, Andrey (2020). Proto-Macro-Jê: um estudo reconstrutivo (Tese de doutorado em linguística). Brasília: Universidade de Brasília, Brasília. https://repositorio.unb.br/handle/10482/38893

Nikulin, Andrey; Salanova, Andrés Pablo (2019). Northern Jê verb morphology and the reconstruction of finiteness alternations. International Journal of American Linguistics 85(4): 533-67. https://doi.org/10.1086/704565

Nimuendajú, Curt (1946). The Eastern Timbira (University of California Publications in American Archaeology and Ethnology, 41.) Berkeley/Los Angeles: University of California Press. http://www.etnolinguistica.org/biblio:nimuendaju-1946-timbira

Nonato, Rafael; Suyá, Jamtô; Suyá, Kawiri (2012). Dicionário Kĩsêdjê-português. Rio de Janeiro: Museu do Índio. http://prodoclin.museudoindio.gov.br/images/conteudo/kisedje/dicionario_kisedje1.pdf

Oliveira, Christiane da Cunha (2003). Lexical categories and the status of descriptives in Apinajé. International Journal of American Linguistics 69(3): 243-274. https://doi.org/10.1086/381336

Oliveira, Christiane da Cunha (2005). The language of the Apinajé people of Central Brazil (Tese de doutorado em linguística). Eugene: University of Oregon. http://www.etnolinguistica.org/tese:oliveira-2005

Passos, João Lucas Moraes (2018). O movimento mẽbêngôkre: andando, nomeando e assentando sobre a terra (Dissertação de mestrado em antropologia). Brasília: Universidade de Brasília. https://repositorio.unb.br/handle/10482/32247

Pries, Stanley T. (2008). Dicionário Gavião-Krikati. Mimeo.

Reis Silva, Maria Amélia (2001). Pronomes, ordem e ergatividade em Mebengokre (Kayapó) (Dissertação de mestrado em linguística). Campinas: Universidade Estadual de Campinas. http://repositorio.unicamp.br/jspui/handle/REPOSIP/270519

Ribeiro Silva, Nandra (2020). Reconstrução fonológica do Proto-Timbira (Tese de doutorado em estudos linguísticos). Belém: Universidade Federal do Pará.

Sá Amado, Rosane de (2004). Aspectos morfofonológicos do Gavião-Pykobjê (Tese de doutorado em linguística). São Paulo: Universidade de São Paulo. https://repositorio.usp.br/item/001413326

Salanova, Andrés Pablo; Nikulin, Andrey (2020). A história que conta o léxico Mẽbêngôkre. Revista de Letras Norte@mentos 13(33): 52-106. http://sinop.unemat.br/projetos/revista/index.php/norteamentos/article/view/4228

Seki, Lucy (2000). Gramática do Kamaiurá: língua Tupi-Guarani do Alto Xingu. Campinas: Editora da UNICAMP. São Paulo: Imprensa Oficial. http://www.etnolinguistica.org/biblio:seki-2000-gramatica

Suyá, Temptxi; Kaiabi, Kaomi Suyá; Suyá, Gaidoberi; Suyá, Petoroti; Suyá, Hwĩti (1999). Kũsêdjê kapẽrẽ. São Paulo, Brasília: Instituto Socioambiental. https://www.socioambiental.org/pt-br/o-isa/publicacoes/kisedje-kapere-alfabetizacao-na-lingua-suya

Suyá, Wetanti, Suyá, Mayuri; Suyá, Kokatá; Suyá, Ropkrãsê; Suyá, Nhikraberi; Suyá, Mbentykrari; Suyá, Kaiusa; Suyá, Weteme Trumai; Suyá, Amtôtxinti; Suya, Tepmtongôkatxi Trumai; Suya, Koiroro; Suyá, Teptanti Juruna; Kaiabi, Poãn Trumai; Suyá, Ngáty Kaiabi (2012). Wâtân khwê wa nhõ twâ. Livro sobre nutrição. Belo Horizonte: Literaterras. http://www.letras.ufmg.br/padrao_cms/documentos/eventos/indigena/Watan\%20Khwe\%20wa\%20nho \%20twa\%20-\%20Kisedje.pdf

Recebido: 5/10/2021

Versão revista e corrigida: 15/11/2021

Aceito: 29/11/2021

Publicado: 3/12/2021 